\title{
LIPID PROFILE INPATIENTS WITH RHEUMATOID ARTHRITIS: CORRELATION WITH DISEASE ACTIVITY
}

\author{
Ali Mahmoud Kasem, MD*; Esam Mohammed Abo Al-Fadl, MD**; HananSayed \\ MohammedAbo-Zeid, MD**; Ashraf AhmedAbd El-Latif, MD***; EbtesamKhalaf \\ Ali Fayez, MSc**. \\ * Department of Internal Medicine- Faculty of Medicine- Sohag University; ** Department \\ ofPhysical medicine,Rheumatology and Rehabilitation- Faculty of Medicine- Sohag University; \\ *** Department of Dermatology, Venereology and Andrology- Faculty of Medicine- Sohag \\ University.
}

\section{ABSTRACT}

Objectives:To study changes in lipid profile in patients with rheumatoid arthritis (RA) and to evaluate the relation between lipid profile and disease severity of RA.

Design: Cross-sectional study.

Patients:Patients with rheumatoid arthritis (RA) according to 2010 ACR/EULAR classification criteria for RA $(n=150)$.

Methods: Demographic data, arthritis history, medical and therapeutic history were evaluated. Disease activity was evaluated using DAS28 (ESR). Immunological investigations included RF, ESR, CRP, and anti-CCP.Lipid profile levels were measured.

Results:Raised TG was found in $38(25.3 \%)$ of patients, raised TC was found in 69 (46 $\%)$ of patients and decreased HDL-C was detected in $85(56.7 \%)$ of the patients.

Key words: rheumatoid arthritis, lipid profile, DAS28.

\section{INTRODUCTION}

Rheumatoid arthritis (RA) is one of the most prevalent chronic inflammatory diseases. It primarily involves the joints,with extra-articular manifestations $^{(\mathbf{1})}$. RA is the most common inflammatory arthritis (2). Patients with RA have high mortality rate when compared to the general population, with cardiovascular disease (CVD) contributing up to $50 \%$ of all deaths ${ }^{(3)}$.The main determinants of cardiovascular risk in the general population are the concentrations of serum low density lipoprotein (LDL) and high density lipoprotein (HDL) cholesterol $^{(4)}$.

In RA, high-grade inflammation and associated factors, such as increased levels of CRP and inflammatory cytokines, can influence commonly measured lipid levels, leading to their misinterpretation ${ }^{(5)}$.Studies in patients with early RA demonstrate normal or mildly elevated total cholesterol (TC), LDL and triglycerides (TG), associated with decreased HDL levels (6, 7). By contrast,highly active RA is associated with decreased TC and LDL levels ${ }^{(\mathbf{6})}$.

The dynamic changes that occur in traditionally assessed lipid profiles during the course of RA are influenced by various factors. Quantitative and qualitative changes in lipid homeostasis mirror the action and counteraction of the inflammatory disease and the evoked metabolic alterations ${ }^{(8,9)}$. The aim of this study was tostudy changes in lipid profile in patients with RA and to evaluate the relation between lipid profile and disease severity of RA.

\section{PATIENTS AND METHODS:}

This study included 150patients; diagnosed as having RA according to the 2010 ACR/EULAR classification criteria forRA (10); attending Rheumatology clinics at Sohag University Hospitals. The 
study was approved by Ethical and Research committees at Faculty of Medicine, Sohag University. An informed written consent was obtained.

\section{Exclusion criteria:}

$凶$ Age less than 16 years.

冈 Patients with other inflammatory diseases.

凶 Patients with familial dyslipidemia or diseases known to cause dyslipidemia e.g. hypothyroidism, nephrotic syndrome.

凶 Female patients on oral contraceptive pills and pregnant patients.

Methods: Patients were evaluated as follow:

\section{I-Initial evaluation:}

Demographic data (age, sex, residency, occupation and smoking) were obtained from all participants. Arthritis history including age at onset, disease course and duration, and morning stiffness was recorded. Medical history (DM, hypertension, CVDs, respiratory, renal and hepatic diseases) was documented for all patients. Therapeutic history (NSAIDs, DMARDs, glucocorticoid use, cardiovascular drugs, and hypoglycemic drugs) was discussed with all patients.

II- Joint examination and disease activity:

Examination of 28 joints of the hands, wrists, elbows, shoulders, and knees was done with count of the swollen and tender joints to calculate DAS28. The disease activity was evaluated using DAS28 (ESR) according to the equation [DAS28 $(E S R)=0.56 \times \sqrt{ }($ TJC 28$)+0.28 \sqrt{ }(\mathrm{SJC}$ $28)+0.70 \times \ln (\mathrm{ESR})+0.014 \times \mathrm{GH}$ (range, 0-9)]. High disease activity was considered as DAS28 $>5.1$, moderate as DAS28 $>3.2-\leq 5.1$, and low disease activity in the range $2.6-3.2$. DAS28 $\leq 2.6$ indicated disease remission ${ }^{(11)}$.

III- Laboratory investigations:

III.A) Immunological tests:

1-Rheumatoid factor (RF): It was measured in patients' sera by rapid latex agglutination test using AVITEX RF kit (Omega diagnostics LTD, Scotland, United Kingdom).Positive results were considered at RF serum

concentration above $8 \mathrm{IU} / \mathrm{ml}$.

2- Erythrocyte Sedimentation Rate (ESR): ESR was measured in the anticoagulated blood of the patients by Wintrobe's method. The reference range of first hour ESR was $3-5 \mathrm{~mm} / \mathrm{hr}$ (for females) and 7 $12 \mathrm{~mm} / \mathrm{hr}$ (for males).

3-C-reactive protein(CRP): It was measured in patients' sera by rapid latex agglutination test using AVITEX CRP kit (Omega Diagnostics LTD, Scotland, United Kingdom).Positive results were considered at CRP serum concentration above $6 \mathrm{mg} /$ Litre.

4- Anti-cyclic citrullinated peptides (Anti-CCP):was measured by a chemiluminescentmicroparticle immunoassay using ARCHITECT AntiCCP Reagent Kit "1P65" (Axis-Shield Diagnostics LTD, Dundee, United Kingdom). Values more than $5 \mathrm{IU} / \mathrm{ml}$ were considered positive.

III.B) Lipid profile:Serum TC, HDL-C and TG were assessed by enzymatic colorimetric methods using commercially available kits on Cobas $\mathrm{C} 311$ analyzer (Roche Diagnostics GmbH, Germany).TC between 50 and $200 \mathrm{mg} / \mathrm{dl}$, TG between 40 and $150 \mathrm{mg} / \mathrm{dl}$, HDL-C more than 35 $\mathrm{mg} / \mathrm{dl}$ and LDL-C less than $110 \mathrm{mg} / \mathrm{dl}$ were considered normal values.

IV- Statistical analysis:

Data were analyzed usingStatistical Package for Social Sciences soft ware program (SPSS, version 24). Qualitative variables were recorded as frequencies and percentages and were compared by chi-square test.Quantitative variables were presented as means \pm standard deviation (SD)for normally distributed data and median with interquartile range (IQR) for non-normally distributed dataand were compared by independent $t$ test.Pearson's correlation test was used to study the correlation between DAS-28 and different parameters of lipid pofile. $P$ value $<0.05$ was considered statistically significant. 


\section{RESULTS}

The mean age \pm SD of the patients was $45.01 \pm 11.05$ years, with $126(84 \%)$ of themwere females, and $102(68 \%)$ were from rural areas.Only $17(11.3 \%)$ of the patients were smokers. The mean \pm SD age at the disease onset of the study population was $35.66 \pm 10.60$ years. The mean \pm SD duration of the disease was $9.60 \pm 7.35$ years. The course of the disease was progressive in all patients. Morning stiffness was recorded in $77(51.3 \%)$ of the study population.

History of hypertension was found in $28(18.7 \%)$ of the study population and DM was documented in $19(12.7 \%)$. History of CVDs was found in $4(2.7 \%)$ of the study population; with history of ischemia in 3 patients and history of myocardial infarction in one patient. History of stroke was found in 1 patient $(0.7 \%)$.

History of use of NSAIDs was found in $146(97.3 \%)$ of the study population. Use of steroids (prednisone/ prednisolone) was demonstrated in 61 (40.7\%). Regarding DMARDs; most patients $(61.3 \%)$ were using two drugs. Hydroxychloroquinewas used by $112(74.7 \%)$, methotrexate by 106 (70.7\%),leflunomideby 46(30.7\%), and sulfasalazine by $31(20.7 \%)$ of the study population.

The mean values of DAS28 and its different components are shown in table 1. Categories of disease activity in the study population according to DAS28 are demonstrated in table 2.

Table 1: Mean values of DAS28 and its different components in the study population $(n=150)$.

\begin{tabular}{|l|l|}
\hline \multicolumn{1}{|c|}{ Parameter } & \multicolumn{1}{c|}{ Mean \pm SD } \\
\hline Number of tender joints & $\mathbf{5 . 5 3} \pm \mathbf{3 . 8 8}$ \\
\hline Number of swollen joints & $\mathbf{2 . 2 3} \pm \mathbf{2 . 5 8}$ \\
\hline erythrocyte sedimentation rate & $\mathbf{5 0 . 8 9} \pm \mathbf{2 7 . 0 3}$ \\
\hline visual analogue scale (VAS 0-100) & $\mathbf{5 1 . 0 5} \pm \mathbf{2 5 . 5 8}$ \\
\hline DAS-28 & $\mathbf{4 . 9 0} \pm \mathbf{1 . 2 2}$ \\
\hline
\end{tabular}

Table 2: Categories of disease activity in the study population $(n=150)$ according to DAS28.

\begin{tabular}{|l|c|}
\hline \multicolumn{1}{|c|}{ Parameter } & Frequency (Percentage) \\
\hline RA in remission (DAS $<2.6)$ & $4(2.7 \%)$ \\
\hline Low disease activity (DAS 2.6-3.2) & $13(8.7 \%)$ \\
\hline Moderate disease activity (DAS 3.2-5.1) & $55(36.7 \%)$ \\
\hline High disease activity (DAS $>$ 5.1) & $\mathbf{7 8 ( 5 2 \% )}$ \\
\hline
\end{tabular}

The CRP was positive in $136(90.7 \%)$ of the study population, with median value of 12 $\mathrm{mg} / \mathrm{L}$ (IQR: $8-25 \mathrm{mg} / \mathrm{L}$ ). The RF was positive in $97(64.7 \%)$ of the study population, with median value of $36 \mathrm{IU} / \mathrm{ml}$ (IQR: $8-128 \mathrm{IU} / \mathrm{ml})$. The anti-CCP was positive in $99(66 \%)$ of the study population.

The mean \pm SD level of TG was $124.64 \pm 39.55 \mathrm{mg} / \mathrm{dl}$, TC was $193.02 \pm 42.42 \mathrm{mg} / \mathrm{dl}$, and HDL-C was $46.7 \pm 8.81 \mathrm{mg} / \mathrm{dl}$.Raised TG was found in $38(25.3 \%)$, raised TC was found in 69 (46\%), and decreased HDL-C was detected in 85 (56.7\%) of the patients.Correlations between DAS28-ESR parameters and lipid profile are shown in table 3. There was significant positive correlation between DAS28 score and cholesterol; and negative correlation between DAS28 score and HDL. 
Table 3: Correlations between DAS28-ESR parameters and lipid pofile.

\begin{tabular}{|c|c|c|c|c|c|c|}
\hline \multicolumn{2}{|l|}{ Parameter } & $\begin{array}{c}\text { Tender } \\
\text { joints }\end{array}$ & $\begin{array}{c}\text { Swollen } \\
\text { joints }\end{array}$ & ESR & $\begin{array}{l}\text { VAS } \\
0-100\end{array}$ & $\begin{array}{c}\text { DAS } 28 \\
\text { Score }\end{array}$ \\
\hline \multirow[t]{2}{*}{ Triglycerides } & $\# \mathbf{r}$ & -0.016 & -0.026 & 0.008 & 0.031 & 0.017 \\
\hline & ${ }^{*} \mathbf{p}$ & 0.847 & $\mathbf{0 . 7 5 7}$ & 0.925 & 0.711 & $\mathbf{0 . 8 3 7}$ \\
\hline \multirow[t]{2}{*}{ Cholesterol } & $\# \mathbf{r}$ & 0.183 & 0.145 & 0.164 & 0.231 & 0.228 \\
\hline & $* \mathbf{p}$ & 0.025 & 0.077 & 0.045 & 0.004 & 0.005 \\
\hline \multirow[t]{2}{*}{ High density lipoprotein-cholesterol } & $\# \mathbf{r}$ & -0.129 & -0.090 & -0.187 & -0.129 & -0.179 \\
\hline & $* \mathbf{p}$ & 0.116 & 0.273 & 0.022 & 0.116 & 0.029 \\
\hline
\end{tabular}

$* \mathrm{P}$ value $<0.05$ was significant

\# r (Correlation coefficient).

\section{DISCUSSION}

In the current study; most patients were females $(84 \%)$ with mean age $45.01 \pm$ 11.05 years and disease duration $9.60 \pm 7.35$ years. More than half of patients $(52 \%)$ had severe disease activity according to DAS28. This may be explained by the setting from which they were recruited (a tertiary-level referral hospital) and no use of biological therapy in any of the patients.

None of the rheumatoid patients in this study was treated for dyslipidemia. However;raised TG was found in 38 (25.3 $\%$ ) of patients, raised TC was found in 69 (46\%) of patients and decreased HDL-C was detected in $85(56.7 \%)$ of the patients. The increased levels of dyslipidemia in RA patients were previously reported ${ }^{(4,12,13)}$. A recent study reported high prevalence of undiagnosed hypercholesterolemia in patients with RA (14). These findings demonstrate the importance of searching for dyslipidemias in rheumatoid patients in order to decrease CVD events and allcause mortality.

In this study;the most common lipid abnormality was decreased HDL. This is in accordance with previous reports ${ }^{(4,12)}$. This is in contrast to that, reported by Nisar et al. where the commonest reported abnormality was high cholesterol $^{(15)}$.

In the current; there was positive correlation between cholesterol level and DAS28, and negative correlation between DAS28 and HDL-C levels. This was in accordance with previous studies demonstrating correlations between disease activity and dyslipidemias (16-18). This finding may reflect the role of inflammation in dyslipidemias in rheumatoid patients.

\section{REFERENCES}

1. Smolen JS, Aletaha D and Mcinnes IB: Rheumatoid arthritis.Lancet. 2016; 388(10055): 2023-38.

2. Silman AJ and Pearson JE: Epidemiology and genetics of rheumatoid arthritis.Arthritis Res. 2002; 4 Suppl 3: S265-72.

3. Faden G, Viapiana O, Fischetti F, Faganello G, Gatti D: Cardiovascular risk stratification and management of patients with rheumatoid arthritis in clinical practice: the "EPIDAURO registry".Int $J$ Cardiol. 2014; 172(2): 534-6.

4. Erum U, Ahsan T and Khowaja D: Lipid abnormalities in patients with Rheumatoid Arthritis.Pak J Med Sci. 2017; 33(1): 227230.

5. Ferraz-Amaro I, Gonzalez-Juanatey C, Lopez-Mejias R, Riancho-Zarrabeitia $L$ and Gonzalez-Gay MA: Metabolic syndrome in rheumatoid arthritis.Mediators Inflamm. 2013; 2013: 710928.

6. Charles-Schoeman C, Fleischmann R, Davignon J, Schwartz H, Turner SM: Potential mechanisms leading to the abnormal lipid profile in patients with rheumatoid arthritis versus healthy volunteers and reversal by tofacitinib.Arthritis Rheumatol. 2015; 67(3): 616-25. 
7. Choy $\mathbf{E}$ and Sattar N: Interpreting lipid levels in the context of high-grade inflammatory states with a focus on rheumatoid arthritis: a challenge to conventional cardiovascular risk actions. Ann Rheum Dis. 2009; 68(4): 460-9.

8. Robertson J, Peters MJ, Mcinnes IB and Sattar N: Changes in lipid levels with inflammation and therapy in RA: a maturing paradigm.Nat Rev Rheumatol. 2013; 9(9): 513-23.

9. Myasoedova E, Crowson CS, Kremers HM, Roger VL, Fitz-Gibbon PD: Lipid paradox in rheumatoid arthritis: the impact of serum lipid measures and systemic inflammation on the risk of cardiovascular disease.Ann Rheum Dis. 2011; 70(3): 482-7.

10. Aletaha D, Neogi T, Silman AJ, Funovits J, Felson DT: 2010 rheumatoid arthritis classification criteria: an American College of Rheumatology/European League Against Rheumatism collaborative initiative.Ann Rheum Dis. 2010; 69(9): 1580-8.

11. Jung YO and Kim HA: Recent paradigm shifts in the diagnosis and treatment of rheumatoid arthritis.Korean $J$ Intern Med. 2012; 27(4): 378-87.

12. Karvounaris SA, Sidiropoulos PI, Papadakis JA, Spanakis EK, Bertsias GK: Metabolic syndrome is common among middle-to-older aged Mediterranean patients with rheumatoid arthritis and correlates with disease activity: a retrospective, crosssectional, controlled, study.Ann Rheum Dis. 2007; 66(1): 28-33.
13. Galarza-Delgado DA, Azpiri-Lopez JR, Colunga-Pedraza IJ, Cardenas-De La Garza JA, Vera-Pineda R: Prevalence of comorbidities in Mexican mestizo patients with rheumatoid arthritis. Rheumatol Int. 20

14. Van Breukelen-Van Der Stoep DF, Van Zeben D, Klop B, Van De Geijn GJ, Janssen HJ: Marked underdiagnosis and undertreatment of hypertension and hypercholesterolaemia in rheumatoid arthritis.Rheumatology (Oxford). 2016; 55(7): 1210-6.

15. Nisar A, Rasheed U, Aziz W and Farooqi AZ: Prevalence of dyslipidemias in autoimmune rheumatic diseases.J Coll Physicians Surg Pak. 2012; 22(4): 235-9.

16. Attar SM: Hyperlipidemia in rheumatoid arthritis patients in Saudi Arabia. Correlation with C-reactive protein levels and disease activity.Saudi Med J. 2015; 36(6): 685-91.

17. Sheng X, Murphy MJ, Macdonald TM and Wei L: Effectiveness of statins on total cholesterol and cardiovascular disease and all-cause mortality in osteoarthritis and rheumatoid arthritis.J Rheumatol. 2012; 39(1): 32-40.

18. Solomon DH, Reed GW, Kremer JM, Curtis JR, Farkouh ME: Disease activity in rheumatoid arthritis and the risk of cardiovascular events.Arthritis Rheumatol. 2015; 67(6): 1449-55. 
SOHAG MEDICAL JOURNAL LIPID PROFILE INPATIENTS WITH RHEUMATOID ARTHRITIS

Vol. 22 No.1 Jan 2018

Ebtesam Khalaf Ali Fayez 